\title{
Measurement and Analysis of Heterogeneous Strain Fields in Uniaxial Tensile Tests for Boron Steel Under Hot Stamping Conditions
}

\author{
R. Zhang ${ }^{1} \cdot$ Z. Shao ${ }^{1}$ (D) J. Lin $^{1} \cdot$ T.A. Dean ${ }^{2}$
}

Received: 25 June 2019 / Accepted: 10 August 2020 / Published online: 31 August 2020

(C) The Author(s) 2020

\begin{abstract}
Background A significant amount of uniaxial tensile tests has been carried out using Gleeble systems to investigate the viscoplastic deformation of boron steel (22MnB5) under hot stamping conditions. However, due to heat loss through the end clamps, a temperature gradient in the reduced parallel section of dog-bone shaped specimens is inevitable.

Objective In the work reported in this paper, the effect of temperature gradient on measured outcomes is examined.

Methods Uniaxial tensile tests on $1.5 \mathrm{~mm}$ thick boron steel specimens are carried out, under hot stamping conditions and strain fields are quantified using the digital image correlation (DIC) technique. The effect of gauge length on the properties of boron steel, as calculated from observed test results, is determined.

Results Compared with the test at room temperature, a bell-shaped strain distribution occurs within the gauge length even before the appearance of the maximum load. Also, average strain within the gauge length, especially in the later stages, changes with gauge length within the investigated range, and thus, different engineering stress-strain curves and fracture strains are determined. In addition, normalized strain rate is significantly dependent on gauge length, which results in over $16 \%$ difference among the computed flow stresses by using a unified constitutive model.

Conclusions The characterized properties of the material are dependent on gauge length and thus, a testing standard for measuring thermal-mechanical data of materials by using a Gleeble need to be defined.
\end{abstract}

Keywords Boron steel $\cdot$ Hot stamping $\cdot$ Temperature gradient $\cdot$ Uniaxial tensile test $\cdot$ Digital image correlation

\section{Introduction}

In the vehicle manufacturing industry, an increasing demand to improve strength to weight ratio of metallic panel components has stimulated technological development in sheet metal forming [1]. The hot stamping and cold die quenching process (abbreviated as 'hot stamping') has been developed for the manufacture of high-strength steel components $[2,3]$ and complex-shaped light alloy components $[4,5]$. Boron steel is the most commonly used steel grade for hot stamping applications for automobiles [6]. The sheet is heated above its $\mathrm{Ac}_{3}$ temperature followed by soaking for a prescribed time to

Z. Shao

z.shao12@imperial.ac.uk

1 Departmental of Mechanical Engineering, Imperial College London, London SW7 2AZ, UK

2 Departmental of Mechanical Engineering, University of Birmingham, B15 2TT, Birmingham, UK ensure transformation of its microstructure into austenite and is then formed and quenched simultaneously, between cold dies, into a complex-shaped component with a fully martensitic structure with ultra-high strength [7].

To enable accurate material and process modelling of hot stamping, knowledge of the effect of process conditions on constitutive properties of the workpiece material is essential $[8,9]$. Considering the complex temperature profile experienced by workpieces in hot stamping processes, Gleeble thermal-mechanical simulators, which enable accurate control of temperature and testing speed, are commonly used to obtain relevant constitutive data. Merklein et al. [10] investigated thermal and thermal-mechanical properties of boron steel by performing hot tensile tests appropriate to hot stamping processes, using a Gleeble 1500 machine. Li et al. [11] adopted a modified Arrhenius model and an improved Johnson-Cook model to describe hot deformation of boron steel, by regression analysis of true stress-strain curves, determined using a Gleeble 1500D over ranges of temperature, 20 to $900{ }^{\circ} \mathrm{C}$ and strain rate, 0.01 to $10 / \mathrm{s}$. Gui et al. [12] performed hot tensile 
tests on boron steel using a Gleeble 3500 over a temperature range, 700 to $850{ }^{\circ} \mathrm{C}$ and strain rate range, 0.01 to $1 / \mathrm{s}$, and analyzed effects of an Al-Si coating on mechanical properties of the material. Li et al. [13] studied effects of heating rate and soaking temperature on the formation of austenite using a Gleeble 3800. Li et al. [14] also investigated effects of deformation temperature and strain rate on the fracture and work hardening of boron steel by carrying out hot tensile tests over a temperature range, 550 to $850{ }^{\circ} \mathrm{C}$ and strain rate range, 0.01 to $5 / \mathrm{s}$ in a Gleeble machine.

One limitation of testing accuracy in using a Gleeble machine for tensile testing is that, as specimen ends are secured by water-cooled jaws, heat loss occurs and a temperature gradient from mid-length to ends of a specimen arises. A temperature gradient within the reduced parallel section of dog-bone shaped specimens has been reported, which probably affects property characterization [17-19]. Table 1 shows fracture strain and tensile strength, calculated from Gleeble test results, for boron steel at $700{ }^{\circ} \mathrm{C}$ and strain rate $0.1 / \mathrm{s}$, taken from five different publications. It is shown that both fracture strain and tensile strength vary between references and depend on specimen dimensions and gauge length. Gui et al. [12] proposed a method to calibrate the experimental stress-strain data, but the calibration is practically difficult as it is based on an assumption of homogeneous temperature within a small gauge length. In order to provide a means for determining accurately and consistently, high temperature constitutive relations using tensile tests on Gleeble machines, an in-depth understanding of effects of the temperature gradient is required.

To enable analysis and quantification of the effect of the temperature gradient on calculated constitutive relations, details of strain fields within deforming specimens must be recorded. The non-contact strain measurement method of DIC, firstly introduced by Peters and Ranson [20], enables the measurement of strain fields by mathematically mapping displacement of grey intensity patterns, sprayed onto specimen surfaces, between reference and deformed images [21, 22]. Because of the advantages of suitability to large deformation and use of subsets during correlation, speckle patterns have been commonly used in the DIC technique [23]. Martínez-
Donaire et al. [24] generated high contrast stochastic patterns using a customized paint, and measured strain fields in aluminum alloys at room temperature. Güler and Efe [25] adopted the DIC technique to measure strain fields in an aluminum alloy and a steel at room temperature, in which speckle patterns were generated by spraying a black paint background against white paint dots containing $30 \%$ of acrylic paint and $70 \%$ of acetone. Few applications of the DIC technique for strain field measurement in high temperature tests have been found. Shao et al. [26, 27] measured strain fields in aluminum alloy AA6082 at temperatures between 400 and $500{ }^{\circ} \mathrm{C}$ and strain rates between 0.1 and 4 /s, in which high contrast random speckle patterns were generated by using a paint consisting of amorphous precipitated silica and titanium dioxide which can withstand temperatures up to $1093{ }^{\circ} \mathrm{C}$. However, due to serious oxidation of boron steel at high temperature, and burning and peeling off of speckle patterns, no publications have been found for the measurement of strain fields in boron steel at high temperature [28].

The aim of this study is to investigate effects of temperature gradient existing in the reduced parallel section of dog-bone shaped specimens used for uniaxial tensile tests under hot stamping conditions. Particular attention has been paid to effects of gauge length selection on the characterized thermal-mechanical properties of boron steel and on flow stress computations. Uniaxial tensile tests were conducted on specimens cut from $1.5 \mathrm{~mm}$ thick boron steel sheet under hot stamping conditions in a Gleeble 3800 machine, and strain fields were measured using the DIC technique. Based on the measured strain fields, the strain distributions within gauge length under hot stamping conditions were compared with that at room temperature. Then several different gauge lengths were selected and the thermal-mechanical properties of boron steel (e.g. fracture strain) were characterized by using the different gauge lengths. The normalized strain rate within the gauge lengths was also calculated and compared, and the viscoplastic flow stress was computed, with a set of unified viscoplastic constitutive equations, by using the normalized strain rate within the different gauge lengths.

Table 1 The fracture strain and the UTS of boron steel, tested in a Gleeble machine at $700{ }^{\circ} \mathrm{C}$ and strain rate, $0.1 / \mathrm{s}$. Results taken from 5 different publications

\begin{tabular}{|c|c|c|c|c|c|c|c|}
\hline \multirow[t]{2}{*}{ Reference } & \multirow[t]{2}{*}{ Steel grade } & \multicolumn{2}{|l|}{ Specimen dimensions } & \multirow[t]{2}{*}{ Strain measurement } & \multirow[t]{2}{*}{ Gauge length (mm) } & \multirow[t]{2}{*}{ Fracture strain } & \multirow[t]{2}{*}{ UTS (MPa) } \\
\hline & & Parallel length $(\mathrm{mm})$ & Width (mm) & & & & \\
\hline$[15]$ & USIBOR $1500 \mathrm{P}$ & 46 & 12 & Width variation & 26 & 0.48 & 250 \\
\hline$[11]$ & B1500HS & 60 & 10 & Gauge length variation & 30 & 0.47 & 275 \\
\hline$[12]$ & $26 \mathrm{MnB} 5$ & 38.1 & 12.7 & Gauge length variation & 8 & 0.55 & 325 \\
\hline$[16]$ & $22 \mathrm{MnB} 5$ & 34 & 12 & Gauge length variation & 15 & 0.13 & 213 \\
\hline$[14]$ & B1500HS & 50 & 10 & Width variation & 20 & 0.53 & 260 \\
\hline
\end{tabular}




\section{Experimental Programme}

\section{Material and Specimen Design}

The chemical composition of boron steel $22 \mathrm{MnB} 5$ used in this study is given in Table 2 . The geometry and dimensions of the dog-bone shaped specimens, which were milled from $1.5 \mathrm{~mm}$ thick zinc-coated boron steel sheet along the rolling direction, are shown in Fig. 1. The relatively long parallel length was designed to improve the temperature uniformity along the length direction of the specimens. A pair of thermocouples was welded at the mid-length of the specimens to record target temperature at this location. Considering the symmetry of the specimens, the other two pairs of thermocouples were welded only in one direction for temperature distribution measurement, at distances of $10 \mathrm{~mm}$ and $20 \mathrm{~mm}$ from the mid-length.

\section{Experimental Programme}

\section{Experimental Procedure and Data Processing}

Considering the complex temperature profile experienced by a workpiece in hot stamping processes, the tensile tests were conducted in a Gleeble 3800 machine, in which a specimen is heated by its resistance to an electric current provided by water-cooled jaws clamped at each end. The direct resistance heating system is capable of providing smooth control of temperature and heating and cooling rates within a specimen. The temperature profile used in the tests, which mimics industrial hot stamping conditions used for boron steel, is shown in Fig. 2(a) [12, 29]. Specimens, mounted in the Gleeble, were heated to an austenitization temperature of $925^{\circ} \mathrm{C}$ at a heating rate initially of $10{ }^{\circ} \mathrm{C} / \mathrm{s}$, which was reduced to $5{ }^{\circ} \mathrm{C} / \mathrm{s}$ near to target temperature, to avoid overshooting. After soaking for $60 \mathrm{~s}$ to ensure complete austenite transformation, the specimen was quenched at a quenching rate of $60^{\circ} \mathrm{C} / \mathrm{s}$ to a specified forming temperature, held for $2 \mathrm{~s}$ to stabilize temperature and subsequently stretched at a specified strain rate. Figure 2(b) shows the experimental setup in the Gleeble 3800 for the uniaxial tensile tests. A high-speed camera with a constant frame rate of 250 frames per second (fps) was used to capture specimen deformation. A pair of purpose-built wedges was used to ensure that the top surface of specimens was parallel to the camera lens [26]. Two flat-head nozzles connected to an air-cooling system in the Gleeble were used for quenching. A laptop connected to the high-speed camera was used to record the captured images, and the commercial

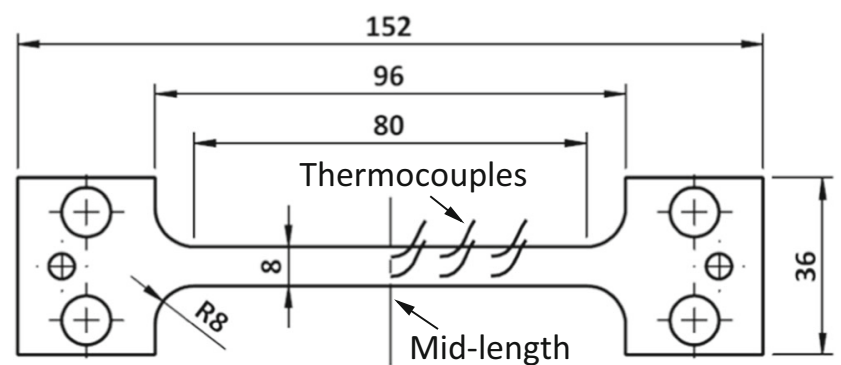

Fig. 1 Geometry and dimensions of dog-bone shaped specimen of boron steel (all dimensions in $\mathrm{mm}$ )

software ARAMIS (GOM, Germany) was adopted for data post-processing.

The tests were performed over the range of temperatures and strain rates shown in Table 3. For comparison, uniaxial tensile tests were also carried out at room temperature at a constant speed of $10 \mathrm{~mm} / \mathrm{min}$, which approximates to $0.2 / \mathrm{s}$. In order to realize the constant target strain rates, the stroke to stretch specimens was determined according to the following Eq. (1) based on an assumption of isothermal deformation [30]:

$\Delta l=l_{0}\left[\exp \left(t \cdot \dot{\varepsilon_{\mathrm{T}}}\right)-1\right]$

where $\Delta l$ is the stroke, $l_{0}$ is original gauge length, $t$ is time and $\dot{\varepsilon}_{\mathrm{T}}$ is target strain rate.

\section{Digital Image Correlation Setup}

In order to extend application of the DIC technique to strain field measurement under the unique conditions of these tests, a novel method for generating robust, high contrast speckle patterns on boron steel surfaces, was developed. Firstly, the zinc coating on the boron steel was removed using 800-grit silicon carbide paper, then the surfaces were roughened slightly by being ground with 80 -grit paper. The random speckle patterns were prepared by spraying a white paint, ULFALX-Ofenfarbe (309310), capable of withstanding temperatures up to $1200{ }^{\circ} \mathrm{C}$ to generate randomly distributed white dots, against a thin layer black background obtained by spraying black paint, ULFALX-Ofenfarbe (309310), with an airbrush operating at 30 psi pressure with about $12 \mathrm{~cm}$ distance from specimen surface. During the tensile tests, a vacuum environment was used to avoid the oxidization of boron steel at the high temperatures.
Table 2 Chemical composition of boron steel $22 \mathrm{MnB} 5$

\begin{tabular}{lllllll}
\hline $\mathrm{C}(\%)$ & $\mathrm{Si}(\%)$ & $\mathrm{Mn}(\%)$ & $\mathrm{P}(\%)$ & $\mathrm{S}(\%)$ & $\mathrm{Cr}(\%)$ & $\mathrm{B}(\%)$ \\
\hline $0.20-0.25$ & $0.20-0.35$ & $1.00-1.30$ & 0.030 & 0.010 & $0.14-0.26$ & $0.0015-0.005$ \\
\hline
\end{tabular}




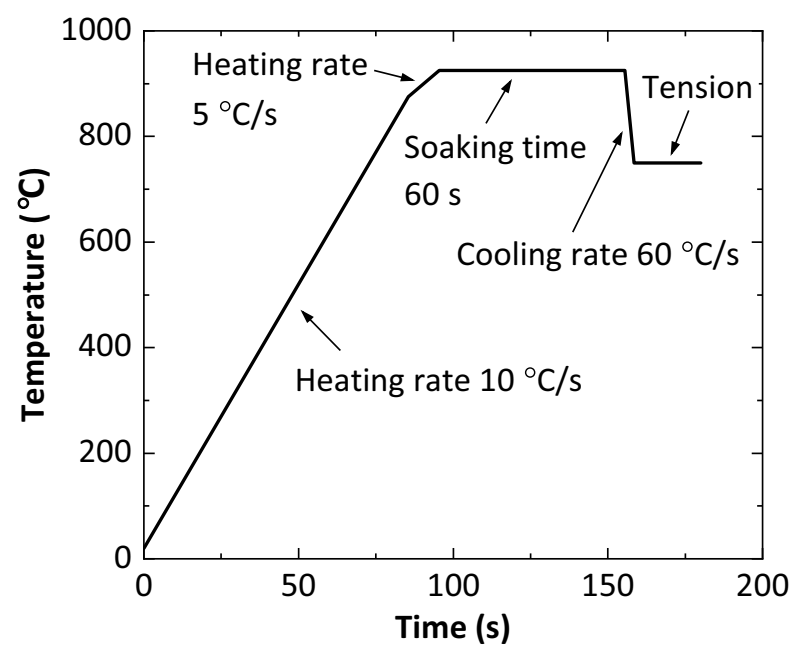

(a)

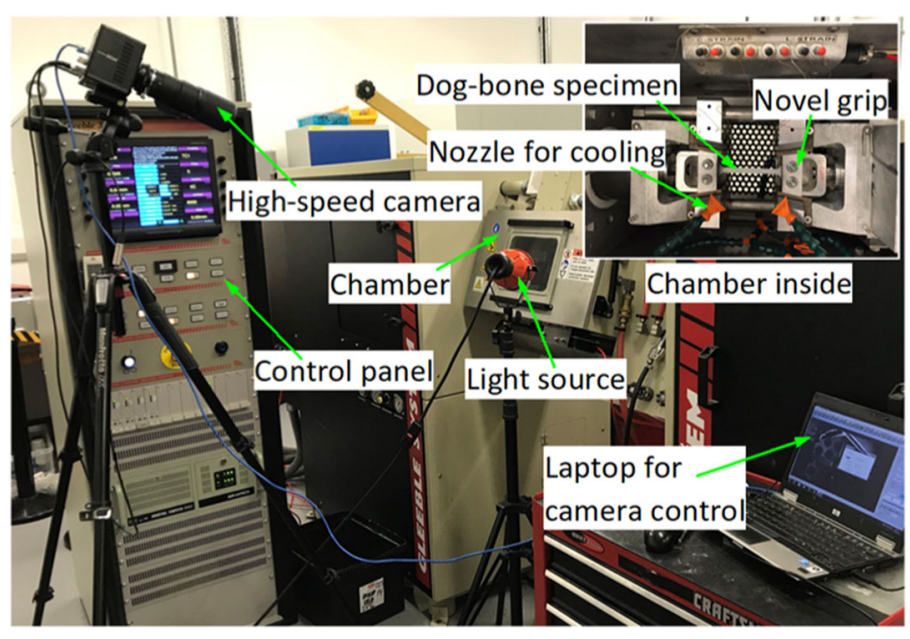

(b)

Fig. 2 (a) Temperature profile and (b) experimental setup for boron steel in the uniaxial tensile tests under hot stamping conditions

\section{Experimental Results and Discussion}

\section{Temperature Distribution and Strain Field Measurement}

Temperature distribution along the length direction of the dogbone shaped specimens, measured when the temperature at specimen mid-length reaches target value, is shown in Fig. 3. It can be seen that temperature decreases at an increasing rate from the mid-length towards the end of the parallel reduced section of the specimen, i.e. an increasing temperature gradient exists along the length of the specimen. Temperature distribution during deformation remains almost the same as that immediately before deformation, given that the closedloop temperature feedback control was used. Referring to Fig. 3, a gauge length of $26 \mathrm{~mm}$ was chosen, in which the maximum temperature gradient is less than $20{ }^{\circ} \mathrm{C}$. Subsequently, the uniaxial tensile tests for boron steel were carried out under the various conditions shown in Table 3.

Measured major engineering strain fields in specimens deformed at $750{ }^{\circ} \mathrm{C}$ and strain rates of $2 / \mathrm{s}$ and $0.2 / \mathrm{s}$, are shown in Figs. 4(a) and (b). The values 0.2, 0.5, 0.8, 0.9 and 1.0 are normalized times $t / t_{\mathrm{f}}$, where $t$ is current time and $t_{\mathrm{f}}$ is time at fracture. The major strain fields in the reduced section of

Table 3 Test programme (' $\sqrt{ }$ ' represents the selected test conditions)

\begin{tabular}{ccccc}
\hline $\begin{array}{l}\text { Strain rate }(/ \mathrm{s}) \\
\text { Temperature }\left({ }^{\circ} \mathrm{C}\right)\end{array}$ & 0.02 & 0.2 & 2 & 0.2 \\
\hline 20 & & & & $\sqrt{ }$ \\
700 & & $\sqrt{ }$ & & \\
750 & $\sqrt{ }$ & $\sqrt{ }$ & $\sqrt{ }$ & \\
850 & & $\sqrt{ }$ & & \\
\hline
\end{tabular}

specimens are heterogeneous even at the normalized time of 0.5 , and with increase of the normalized time, deformation gradually concentrates in the center of specimens, where temperature is the highest (Fig. 3).

Using average strain within the $26 \mathrm{~mm}$ gauge length, engineering stress-strain curves are plotted in Fig. 5. The dashed lines represent the level of the UTS of the material under each condition. As expected, the UTS is higher for either a lower temperature or a higher strain rate, which indicates the viscoplastic nature of the material under the testing conditions. The strain at onset of diffuse necking were determined according to the Considère criterion [31]. As can be seen in Fig. 5, engineering strain at UTS is within a range of $20 \%$ to $30 \%$, and approximately $60 \%$ lower than the fracture strain, for each test condition.

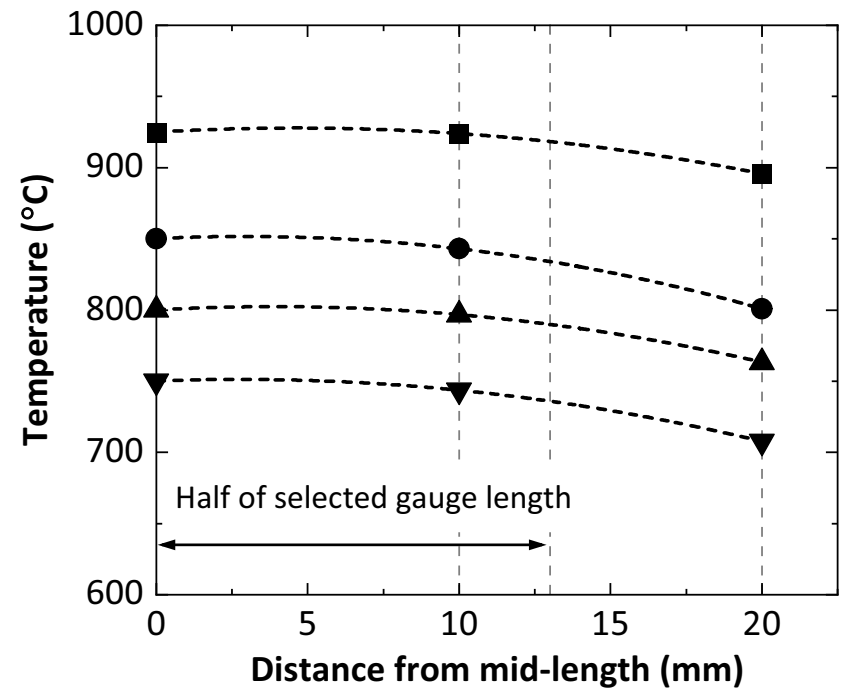

Fig. 3 Temperature distribution along the length of dog-bone shaped specimens 


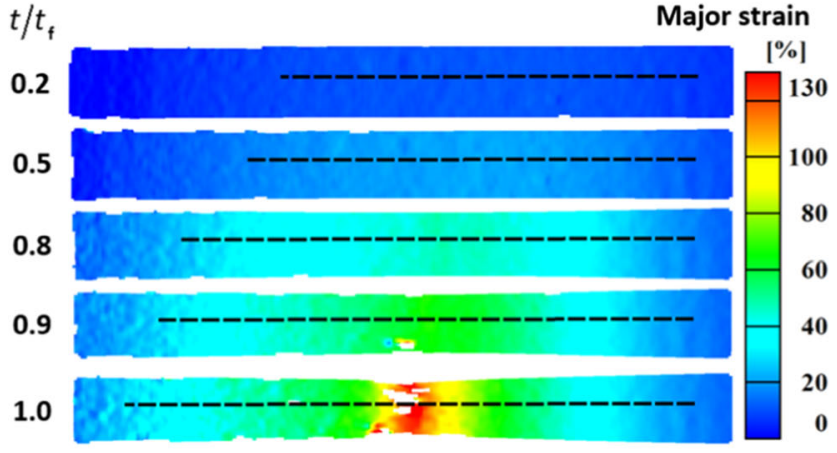

(a)

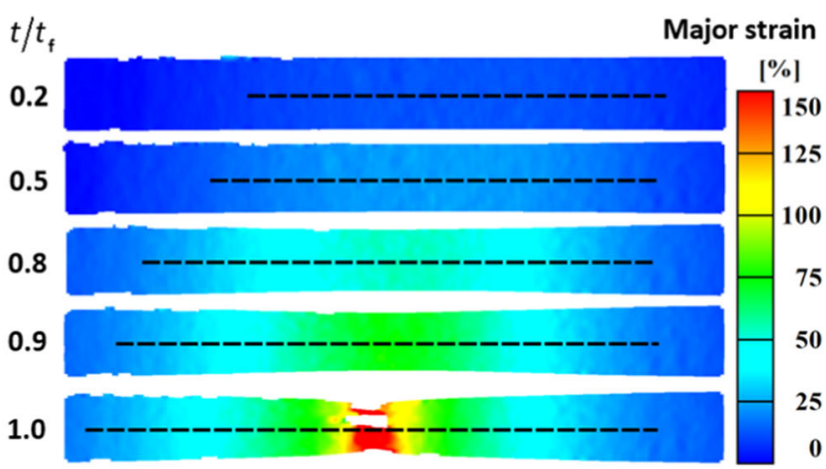

(b)

Fig. 4 Major engineering strain fields in the reduced section of the dog-bone shaped specimens deformed at temperature and strain rate of (a) $750{ }^{\circ} \mathrm{C}$ and $2 / \mathrm{s}$, (b) $750{ }^{\circ} \mathrm{C}$ and $0.2 / \mathrm{s}$, in which the initial length of the section (dashed black) is $40 \mathrm{~mm}$

\section{Effect of Temperature Gradient on Strain Distribution}

The effect of temperature gradient on strain distribution in the reduced section is investigated. Figures 6(a1) to (a6) show strain distribution within a specimen length of initially $40 \mathrm{~mm}$, as indicated as dashed lines in Fig. 4 , for specimens deformed at $20{ }^{\circ} \mathrm{C}$ and $750{ }^{\circ} \mathrm{C}$, at different normalized times $t / t_{\mathrm{f}}$. The strain distribution in the specimen at room temperature is almost uniform until $t / t_{\mathrm{f}}$ reaches 0.8 , and after that, localized deformation occurs at $t / t_{\mathrm{f}}=0.9$ and terminates at $t / t_{\mathrm{f}}=1.0$. In the specimen deformed at $750{ }^{\circ} \mathrm{C}$, however, a bell-shaped strain distribution is observed at $t / t_{\mathrm{f}}=0.3$. That is, strain becomes nonuniform soon after the start of deformation. This is due to the temperature gradient, and deformation is mainly localized at mid-length where temperature is the highest. With increasing the time, nonuniformity of strain significantly increases, and at $t / t_{\mathrm{f}}=0.8$, the strain at mid-length is about $170 \%$ higher than that at the gauge length ends. Figures 6(b) and (c) show relations of stress with time for the tests at $20{ }^{\circ} \mathrm{C}$ and $750{ }^{\circ} \mathrm{C}$, respectively, in which the engineering stresses at each of the normalized times relating to Figs. 6(a1)-(a6) are marked. For the deformation at $20{ }^{\circ} \mathrm{C}$, the maximum load (or engineering stress) occurs at $t / t_{\mathrm{f}} \approx 0.73$. Referring to Figs. 6(a1)-(a6), the strain distribution is uniform before the appearance of the maximum load. However, for the deformation at $750{ }^{\circ} \mathrm{C}$, the maximum load occurs at $t / t_{\mathrm{f}} \approx 0.64$, between stages in Figs. 6(a3) and (a4), and nonuniform strain distribution arises before the maximum load and is maintained throughout deformation, as shown in Figs. 6(a1)-(a6).

The effect of the temperature gradient on the strain distribution in the narrowed length of the specimen, is further quantified by selecting different gauge lengths, situated about midlength and plotting average strain along them as shown in Figs. 7(a) and (b) for $20^{\circ} \mathrm{C}$ and $750{ }^{\circ} \mathrm{C}$ deformation respectively. As shown in Fig. 7(a), the average strain within the different chosen gauge lengths is the same until the time when the maximum load occurs. After this, due to increasing localized deformation, values diverge according to each particular chosen gauge length [32]. As shown in Fig. 7(b), at $750{ }^{\circ} \mathrm{C}$ however, average strains within the different gauge lengths diverge early, before occurrence of maximum load, and with increasing gauge length from 2 to $40 \mathrm{~mm}$, the average strain at the maximum load decreases by about $22 \%$.

The ASTM standard for isothermal uniaxial tensile test specimens, is that the gauge length should be greater than or
Fig. 5 Engineering stress-strain curves of boron steel deformed at (a) $750{ }^{\circ} \mathrm{C}$ and various strain rates, (b) strain rate $0.2 / \mathrm{s}$ and various temperatures

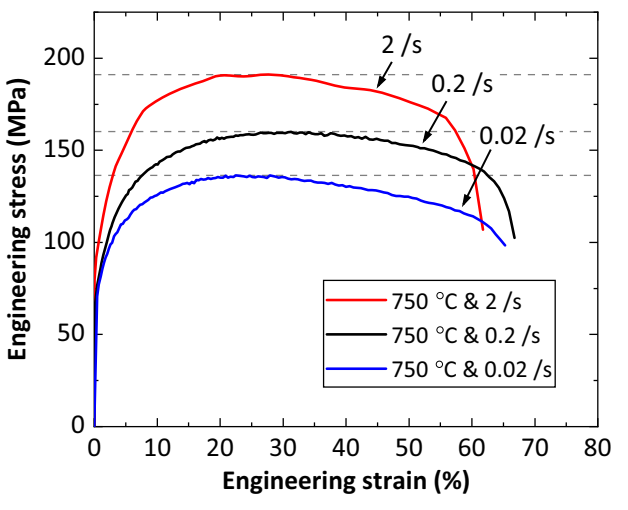

(a)

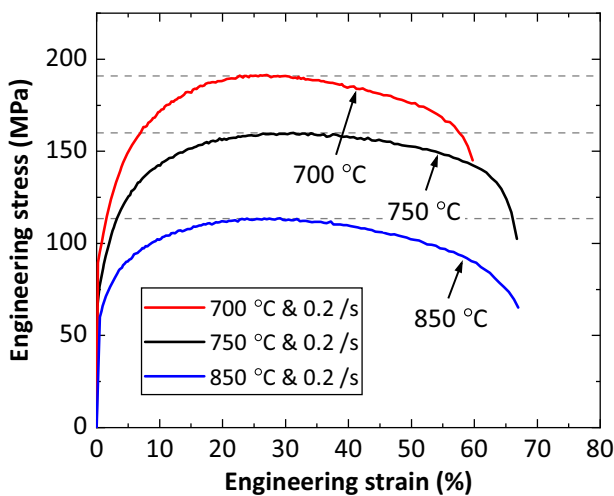

(b) 
Fig. 6 Strain distributions within an initial length of $40 \mathrm{~mm}$ at various normalized times: (a1) $t /$ $t_{\mathrm{f}}=0.3,(\mathrm{a} 2) t / t_{\mathrm{f}}=0.4$, (a3) $t / t_{\mathrm{f}}=$ 0.5, , (a4) $t / t_{\mathrm{f}}=0.8$, (a5) $t / t_{\mathrm{f}}=0.9$ and (a6) $t / t_{\mathrm{f}}=1.0$, and flow stress variation with time at, (b) room temperature $\left(20^{\circ} \mathrm{C}\right)$ and (c) high temperature $\left(750{ }^{\circ} \mathrm{C} \& 0.2 / \mathrm{s}\right)$

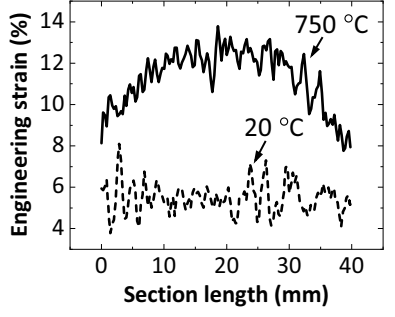

(a1)

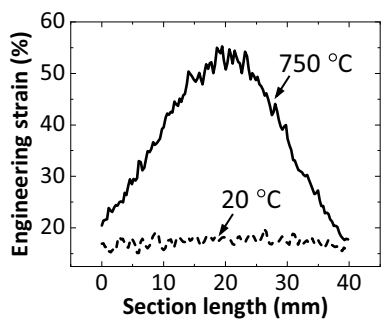

(a4)

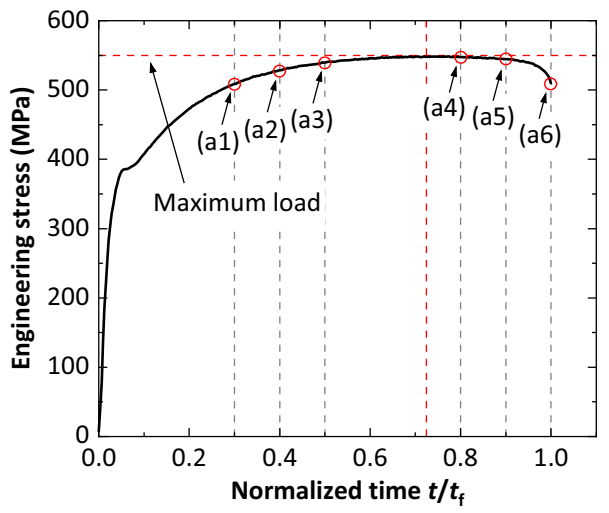

(b)

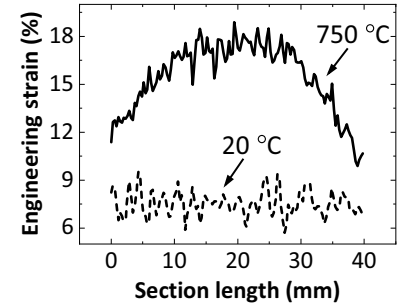

(a2)

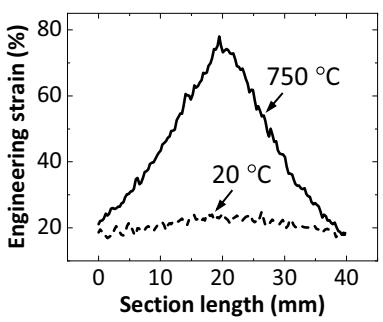

(a5)

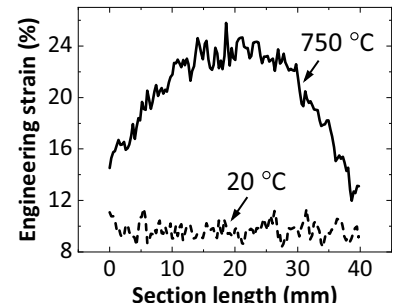

(a3)

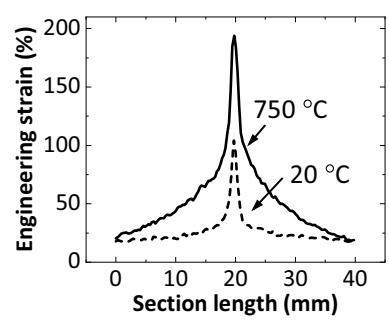

(a6)

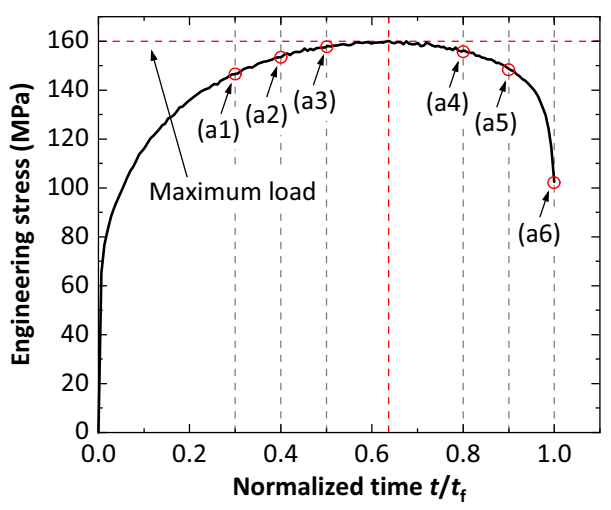

(c)

equal to 4 times specimen width [33]. This is because a high ratio can minimize differences between average strains measured on different gauge lengths after the maximum load, and thus enable characterization of mechanical properties (e.g. fracture strain), which are independent of specimen geometry [34]. Due to the temperature gradient arising in specimens on Gleeble machines, the ASTM criterion for gauge length is not suitable, and using parallel length may underestimate characterized mechanical properties. To overcome this deficiency and ensure accurate material specific mechanical properties can be obtained, it is necessary to redefine gauge length for uniaxial tensile tests on Gleeble machines.

The variation in values of UTS listed in Table 1, measured by different workers, is likely to be attributable to temperature
Fig. 7 Effect of chosen gauge length on measured average strain at, (a) $20{ }^{\circ} \mathrm{C}$ and (b) $750{ }^{\circ} \mathrm{C}$ and $0.2 / \mathrm{s}$

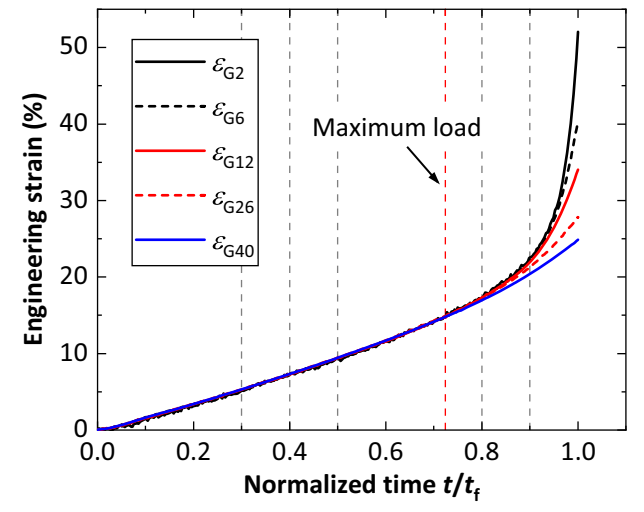

(a)

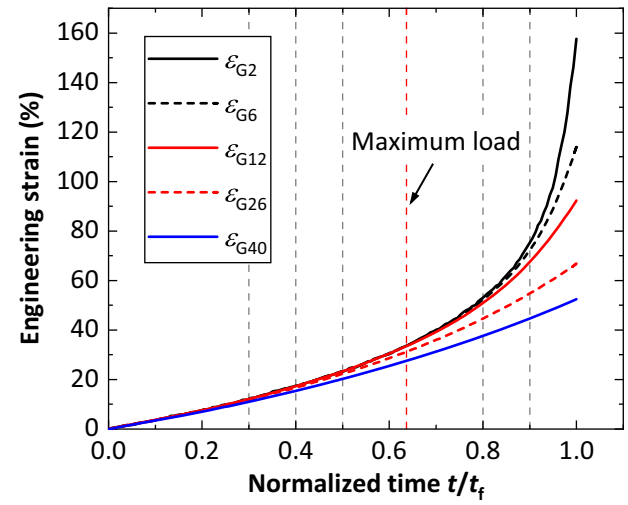

(b) 
Fig. 8 Engineering stress-strain curves based on the various gauge lengths for boron steel deformed at (a), $750{ }^{\circ} \mathrm{C}$ and $2 / \mathrm{s},(\mathrm{b}), 750{ }^{\circ} \mathrm{C}$ and $0.2 / \mathrm{s},(\mathrm{c}), 850^{\circ} \mathrm{C}$ and $0.2 / \mathrm{s}$, and (d), $20{ }^{\circ} \mathrm{C}$

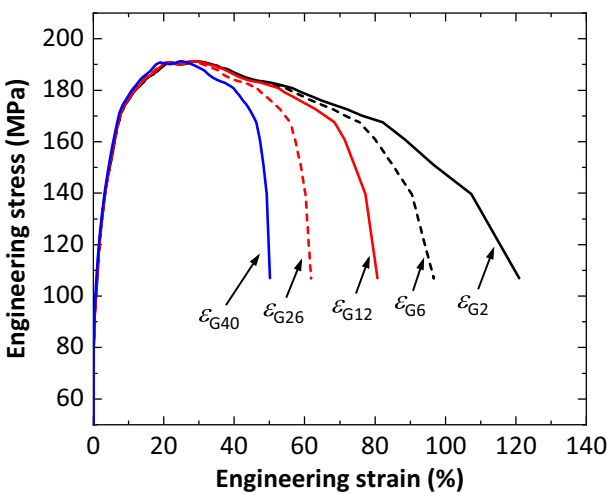

(a)

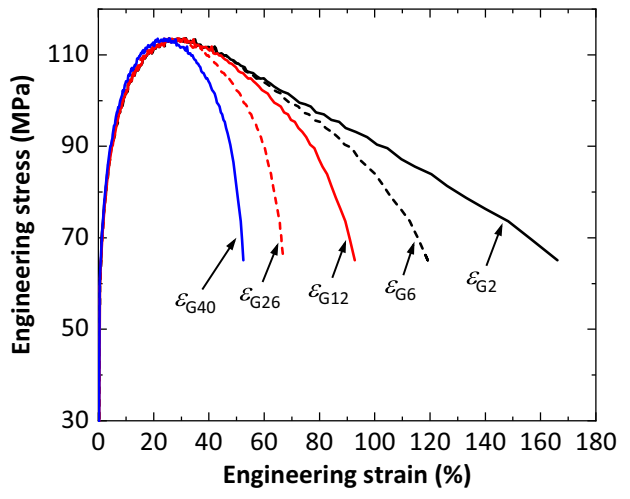

(c)

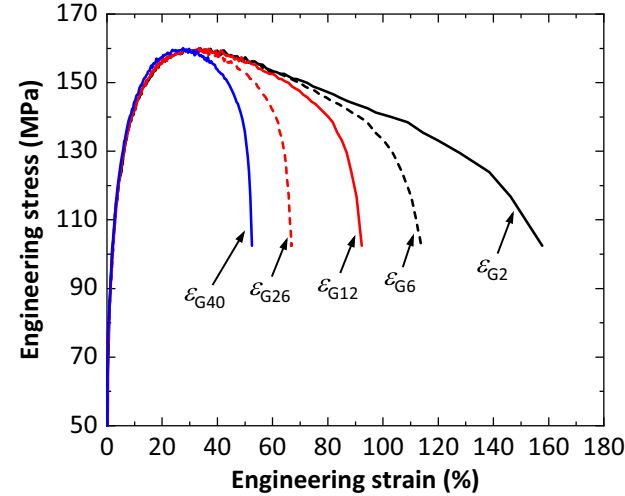

(b)

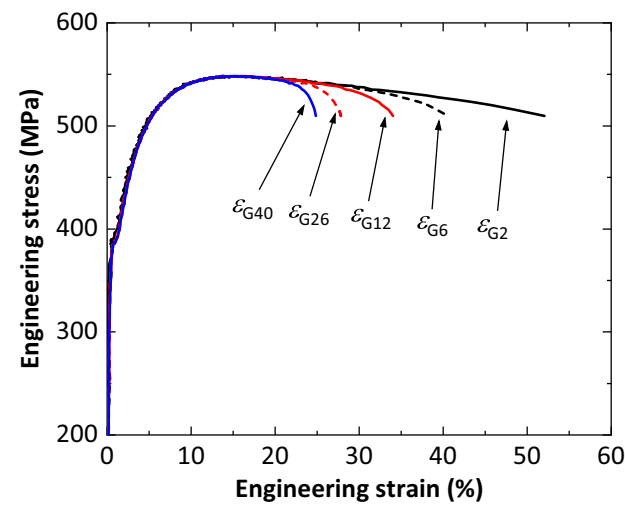

(d) gradient in the reduced width section of the specimens used. Since specimens are heated by direct resistance in the Gleeble, temperature uniformity is highly dependent on specimen geometry and dimensions. Temperature gradients cause bellshaped strain distributions at the start of deformation, as shown in Figs. 6(a1)-(a6), which affect the value of the maximum load sustainable by the specimen material $[35,36]$.

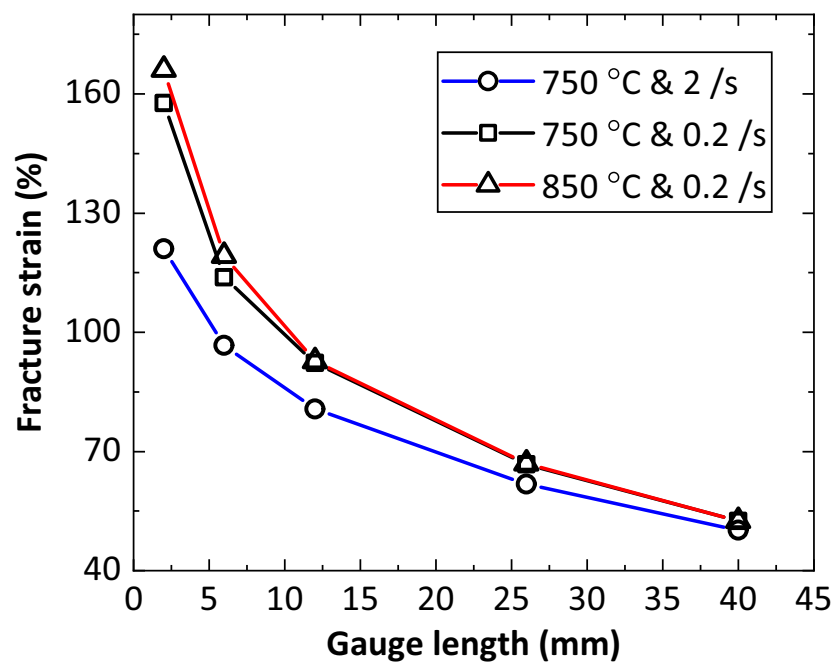

Fig. 9 Effect of gauge length on fracture strain at two different temperatures and strain rates

\section{Effect of Gauge Length on Characterized Thermal- Mechanical Behavior}

\section{Flow Stress and Fracture Strain Curves}

Engineering stress-strain curves are determined using average strain within gauge lengths of 2, 6, 12, 26 and $40 \mathrm{~mm}$ and the results are presented in Fig. 8. As for the average strain-time relationships shown in Fig. 7, the curves in this figure, representing different temperatures, strain rates and gauge lengths are almost same at stresses less than the UTS. Curves for stresses greater than the UTS diverge greatly, depending on gauge length, especially those for deformation at high temperature.

Fracture strains based on the various gauge lengths are plotted in Fig. 9. As expected, fracture strain decreases rapidly and significantly with increasing gauge length for all three test conditions, due to the field of high strain concentrated around fracture, as shown in Fig. 4. For example, fracture strain at $750{ }^{\circ} \mathrm{C}$ and 0.2 /s decreases by $200.4 \%$ with increasing gauge length from 2 to $40 \mathrm{~mm}$. At strain rate $0.2 / \mathrm{s}$, for a particular gauge length, fracture strain at $750{ }^{\circ} \mathrm{C}$ is the same as that at $850{ }^{\circ} \mathrm{C}$, but fracture strain is affected by strain rate at $750{ }^{\circ} \mathrm{C}$. 
Fig. 10 Effect of gauge length on normalized strain rate with respect to time, (a), (c), (e) and true strain, (b), (d), (f) at temperature and strain rate, (a)-(b) $750{ }^{\circ} \mathrm{C}$ and $2 / \mathrm{s}$, (c)-(d), $750{ }^{\circ} \mathrm{C}$ and $0.2 / \mathrm{s}$, and (e)-(f), $750^{\circ} \mathrm{C}$ and $0.02 / \mathrm{s}$

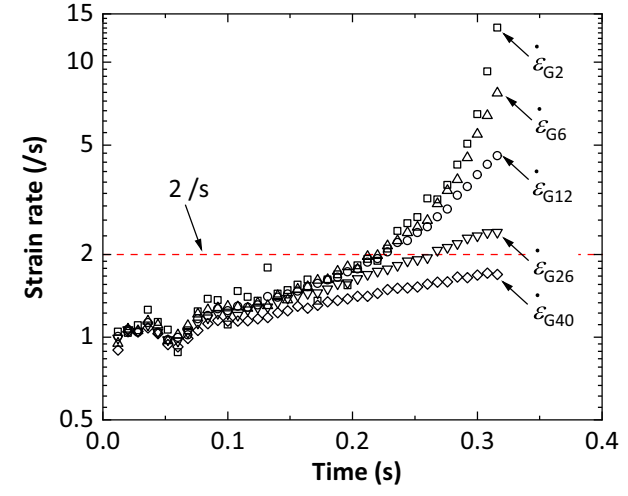

(a)

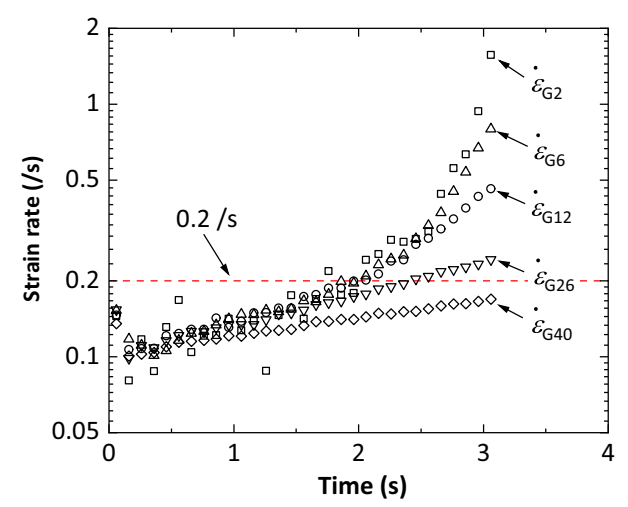

(c)

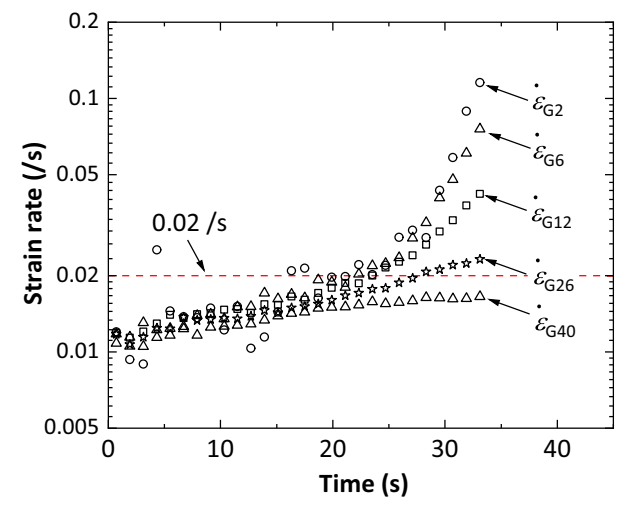

(e)

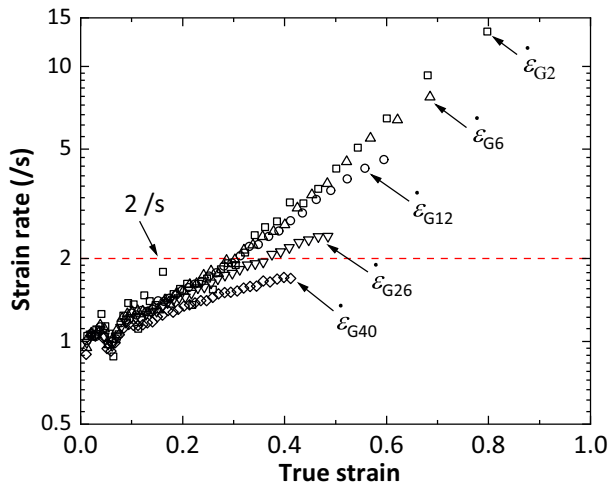

(b)

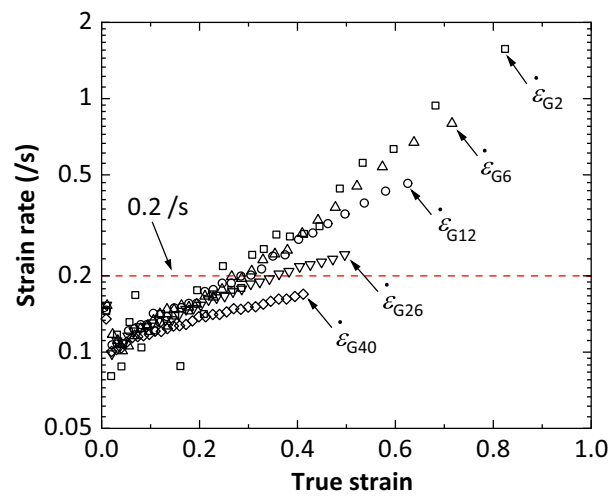

(d)

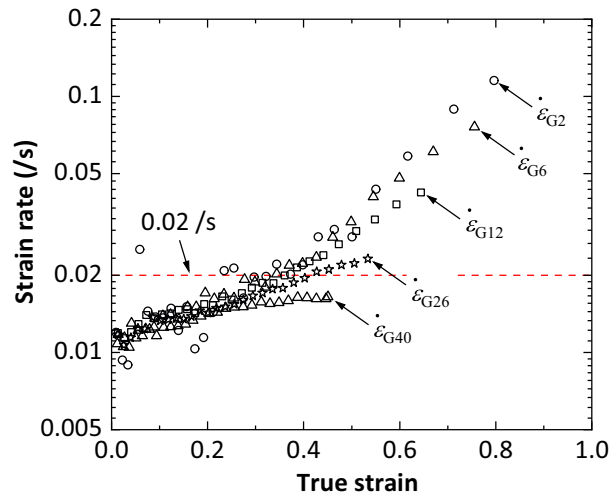

(f)

\section{Computation of Flow Stress}

Normalized Strain Rate Normalized strain rate within various gauge lengths is calculated for tests performed under various conditions and the results are plotted in Fig. 10. In order to reduce the influence of noise from strain field measurement, normalized strain rate at each moment is calculated by fitting four adjacent points of average strain with a first order polynomial function using the least square method. Given that the rate capacity to achieve programmed stroke, in a Gleeble machine, is up to $2000 \mathrm{~mm} / \mathrm{s}$, the effect of acceleration time on measured strain rates is neglectable. Figures 10 (a), (c) and (e) show evolution of normalized strain rate over time, on log scale and Figs. 10(b), (d) and (f) show evolution of normalized strain rate over average strain on log scale, at temperature and strain rate of, $750{ }^{\circ} \mathrm{C}$ and $2 / \mathrm{s}, 750{ }^{\circ} \mathrm{C}$ and $0.2 / \mathrm{s}$ and $750{ }^{\circ} \mathrm{C}$ and 0.02 /s. As shown in Figs. 10(a), (c) and (e), normalized strain rates are lower than the target constant values at initial stages of deformation and increase with increasing deformation. Furthermore, an increasing difference arises between values of normalized strain rate, with increase in value of average strain and higher values of normalized strain rate occur within shorter gauge lengths. For example, at $750{ }^{\circ} \mathrm{C}$ and target strain rate of $2 / \mathrm{s}$, normalized strain rate within $2 \mathrm{~mm}$ 
Table 4 Material constants in the unified viscoplastic constitutive equations for boron steel under hot stamping conditions

\begin{tabular}{lllllll}
\hline$K_{0}(\mathrm{MPa})$ & $k_{0}(\mathrm{MPa})$ & $n_{0_{1}}$ & $B_{0}(\mathrm{MPa})$ & $C_{0}$ & $E_{0}(\mathrm{MPa})$ & $A$ \\
\hline 0.49 & 0.56 & 0.31 & 6.15 & 0.85 & 270.5 & 1.65 \\
$n_{2}$ & $Q_{K}(\mathrm{~J} / \mathrm{mol})$ & $Q_{k}(\mathrm{~J} / \mathrm{mol})$ & $Q_{n_{1}}(\mathrm{~J} / \mathrm{mol})$ & $Q_{B}(\mathrm{~J} / \mathrm{mol})$ & $Q_{C}(\mathrm{~J} / \mathrm{mol})$ & $Q_{E}(\mathrm{~J} / \mathrm{mol})$ \\
5.05 & 32,512 & 18,500 & 17,513 & 22,506 & 1453 & 32,552 \\
\hline
\end{tabular}

gauge length at the final stage of deformation is $13.34 / \mathrm{s}$. This is $567 \%$ higher than the target strain rate, and $689.3 \%$ higher than that within $40 \mathrm{~mm}$ gauge length. In Figs. 10(b), (d) and (f), an exponential increase of normalized strain rate with average strain occurs until fracture, within each gauge length. In initial deformation stages, for a particular value of true strain, normalized strain rate within each gauge length is similar, but at higher values of true strain, strain rate becomes higher the shorter is the gauge length.

Numerically Computed Flow Stress In order to investigate the effect of normalized strain rate within a particular gauge length, on computed flow stress, a set of unified viscoplastic constitutive equations [37, 38], presented as Eq. (2) to Eq. (5) below, which takes into consideration mechanism-based microstructural parameters, such as dislocation hardening, recovery and recrystallisation, has been adopted for calculating flow stress of boron steel under hot stamping conditions [39]. Eq. (2) describes flow stress for an elastic-viscoplastic regime which consists of the threshold stress $k$, the isotropic hardening $R$ and the flow stress related to viscoplastic strain rate (Odqvist's law) [40]. Isotropic hardening $R$ is related to dislocation density and is expressed in Eq. (3), in which $\bar{\rho}$ is a normalized dislocation density and $\bar{\rho}=\frac{\rho-\rho_{\mathrm{I}}}{\rho_{\mathrm{S}}}$, where $\rho_{\mathrm{I}}$ is initial dislocation density and $\rho_{\mathrm{S}}$ is the saturated dislocation density [41]. Eq. (4) describes evolution of normalized dislocation

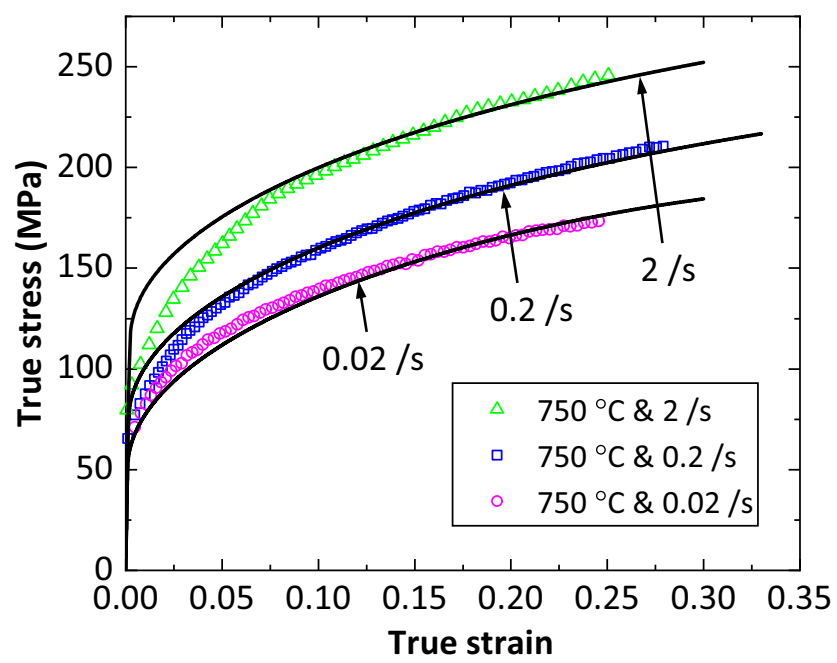

Fig. 11 Computed flow stress curves (solid lines) and experimental data (symbols), for a temperature of $750{ }^{\circ} \mathrm{C}$ and three different strain rates density, in which the first term $A(1-\bar{\rho})\left|\dot{\varepsilon}_{\mathrm{p}}\right|$ represents accumulation of dislocation density due to plastic deformation and dynamic recovery, and the second term $C \bar{\rho}^{n_{2}}$ represents static recovery of dislocation density [39]. The flow stress $\sigma$ is expressed in the Eq. (5) by Hooke's law, where $\varepsilon_{\mathrm{T}}$ is total true strain. The parameters $K, k, n_{1}, B, C$ and $E$ are temperaturedependent material constants which are expressed by taking the form of Arrhenius equations, as illustrated in Eqs. (2)-(11), where $R_{0}\left(R_{0}=8.314 \mathrm{~J} / \mathrm{mol} \cdot \mathrm{K}\right)$ is the universal gas constant, $T$ is absolute temperature, and $A, n_{2}, K_{0}, Q_{K}, k_{0}, Q_{k}$, $n_{0_{1}}, Q_{n_{1}}, B_{0}, Q_{B}, C_{0}, Q_{C}, E_{0}$ and $Q_{E}$ are material constants to be determined from experimental data.

$\dot{\varepsilon_{\mathrm{p}}}=\left(\frac{\sigma-R-k}{K}\right)^{n_{1}}$

$\dot{R}=0.5 B \bar{\rho}^{-0.5} \dot{\rho}$

$\dot{\bar{\rho}}=A(1-\bar{\rho})\left|\dot{\varepsilon}_{\mathrm{p}}\right|-C \bar{\rho}^{n_{2}}$

$\sigma=E\left(\varepsilon_{\mathrm{T}}-\varepsilon_{\mathrm{p}}\right)$

$K=K_{0} \exp \left(\frac{Q_{K}}{R_{0} T}\right)$

$k=k_{0} \exp \left(\frac{Q_{k}}{R_{0} T}\right)$

$n_{1}=n_{0_{1}} \exp \left(\frac{Q_{n_{1}}}{R_{0} T}\right)$

$B=B_{0} \exp \left(\frac{Q_{B}}{R_{0} T}\right)$

$C=C_{0} \exp \left(\frac{-Q_{C}}{R_{0} T}\right)$

$E=E_{0} \exp \left(\frac{Q_{E}}{R_{0} T}\right)$

The above equations are solved by using the forward Euler method [42], and the material constants are calibrated by trial and error in fitting experimental true stress-true strain data, based on a gauge length of $26 \mathrm{~mm}$, before the onset of diffuse necking. The calibrated material constants are shown in Table 4. Computed and experimental flow stress curves for various strain rates, are shown in Fig. 11, in which good agreement between the two types of curve can be seen. 
Fig. 12 Flow stress, numerically computed using normalized strain rate within, gauge length $2 \mathrm{~mm}$ (dashed line) and $40 \mathrm{~mm}$ (hollow symbols), and that using the target constant strain rate (solid line), for boron steel deformed at temperature and target strain rate of (a) $750{ }^{\circ} \mathrm{C}$ and $2 / \mathrm{s}$, (b) $750{ }^{\circ} \mathrm{C}$ and $0.2 / \mathrm{s}$

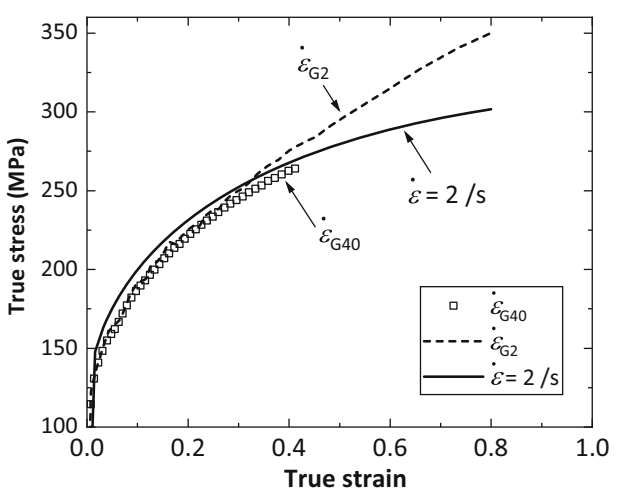

(a)

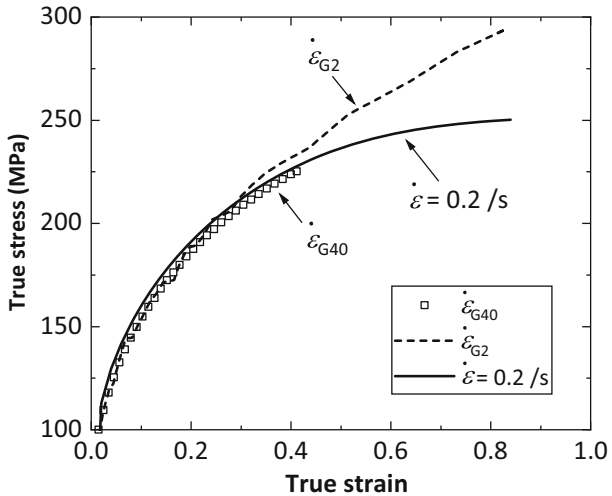

(b)
Using the calibrated material constants in Table 4, flow stresses are computed for a temperature of $750{ }^{\circ} \mathrm{C}$ and target strain rates, $0.2 / \mathrm{s}$ and $2 / \mathrm{s}$, within gauge lengths of $2 \mathrm{~mm}$ and $40 \mathrm{~mm}$. The effect on flow stress of target strain rate and chosen gauge length is shown in Fig. 12. As shown in Fig. 12(a), flow stress computed using the normalized strain rates within a gauge length of $2 \mathrm{~mm}$ reaches $349.8 \mathrm{MPa}$, which is $16 \%$ higher than that by using the target strain rate. A similar situation is shown in Fig. 12(b). This demonstrates that the unified viscoplastic constitutive equations cannot capture flow stress response accurately without considering the effect of the heterogeneous strain field in the gauge length, especially the response in a short gauge length which is fully occupied by large strain.

\section{Conclusions}

In this study, uniaxial tensile tests have been conducted on specimens of boron steel sheet under hot stamping conditions, using a Gleeble 3800 machine and issues concerning strain field measurements using digital image correlation (DIC) technique and temperature gradient effects have been investigated. This provides for better understanding of the variation in existing published elevated temperature constitutive data. In particular, the following conclusions can be drawn:

1) Application of the DIC technique has been successfully extended, for the first time, to strain field measurement in uniaxial tensile tests using a Gleeble materials simulator, for boron steel under hot stamping conditions.

2) Due to the nature of the resistance heating used on Gleeble machines a temperature gradient arises in dog bone shaped specimens and a bell-shaped strain distribution occurs within the gauge length at an early stage of deformation. This causes the calculated value of strain during deformation to be dependent significantly on chosen gauge length.
3) The characterized properties of the material are highly dependent on gauge length and in tests reported in this paper, an increase in gauge length from $2 \mathrm{~mm}$ to $40 \mathrm{~mm}$ results in a difference in calculated fracture strain of more than $200 \%$, and a difference in normalized strain rate within the gauge length of more than $689 \%$.

4) Depending on the chosen gauge length normalized strain rate could be over $567 \%$ higher than the target strain rate and flow stress computed using unified viscoplastic constitutive equations and normalized strain rate for $2 \mathrm{~mm}$ gauge length, is $16 \%$ higher than that using the target strain rate.

5) To bring conformity to elevated temperature tensile testing on Gleeble machines a testing standard which includes gauge length, specimen size and geometry, for measuring thermal-mechanical data needs to be defined.

Acknowledgements Financial supports from EPSRC under the grant number EP/R511547/1 and from EPSRC under the grant number EP/ R001715/1, are gratefully acknowledged by the authors. R. Zhang also appreciates the financial support from the CSC-Imperial Scholarship (Grant no. 201700260069).

\section{Compliance with Ethical Standards}

Declaration of Conflicting Interests The authors declare that there is no conflict of interest.

Open Access This article is licensed under a Creative Commons Attribution 4.0 International License, which permits use, sharing, adaptation, distribution and reproduction in any medium or format, as long as you give appropriate credit to the original author(s) and the source, provide a link to the Creative Commons licence, and indicate if changes were made. The images or other third party material in this article are included in the article's Creative Commons licence, unless indicated otherwise in a credit line to the material. If material is not included in the article's Creative Commons licence and your intended use is not permitted by statutory regulation or exceeds the permitted use, you will need to obtain permission directly from the copyright holder. To view a copy of this licence, visit http://creativecommons.org/licenses/by/4.0/. 


\section{References}

1. Åkerström P (2006) Modelling and simulation of hot stamping. Doctoral thesis, Luleå University of Technology, Luleå, Sweden

2. Bariani P, Bruschi S, Ghiotti A, Turetta A (2008) Testing formability in the hot stamping of HSS. CIRP Annals-Manufacturing Technology 57(1):265-268. https://doi.org/10.1016/j.cirp.2008. 03.049

3. Mori K, Okuda Y (2010) Tailor die quenching in hot stamping for producing ultra-high strength steel formed parts having strength distribution. CIRP Ann 59(1):291-294. https://doi.org/10.1016/j. cirp.2010.03.107

4. Lin J, Balint D, Wang L, Dean TA, Foster AD (2013) Method of forming a component of complex shape from sheet material. United States patent US 2013/0125606 A1, may 23, 2013

5. Bariani PF, Bruschi S, Ghiotti A, Michieletto F (2013) Hot stamping of AA5083 aluminium alloy sheets. CIRP Ann 62(1): 251-254. https://doi.org/10.1016/j.cirp.2013.03.050

6. Billur E, Berglund G, Gustafsson T (2018) History and future outlook of hot stamping. In: Billur E (ed) Hot stamping of ultra highstrength steels. Springer, Cham. https://doi.org/10.1007/978-3-31998870-2 3

7. Karbasian H, Tekkaya AE (2010) A review on hot stamping. J Mater Process Technol 210(15):2103-2118. https://doi.org/10. 1016/j.jmatprotec.2010.07.019

8. Turetta A, Bruschi S, Ghiotti A (2006) Investigation of 22MnB5 formability in hot stamping operations. J Mater Process Technol 177(1-3):396-400. https://doi.org/10.1016/j.jmatprotec.2006.04. 041

9. Mohamed MS, Foster AD, Lin J, Balint DS, Dean TA (2012) Investigation of deformation and failure features in hot stamping of AA6082: experimentation and modelling. Int J Mach Tool Manu 53(1):27-38. https://doi.org/10.1016/j.ijmachtools.2011.07.005

10. Merklein M, Lechler J (2006) Investigation of the thermomechanical properties of hot stamping steels. J Mater Process Technol 177(1-3):452-455. https://doi.org/10.1016/j.jmatprotec. 2006.03.233

11. Li H, He L, Zhao G, Zhang L (2013) Constitutive relationships of hot stamping boron steel B1500HS based on the modified Arrhenius and Johnson-cook model. Mater Sci Eng A 580:330 348. https://doi.org/10.1016/j.msea.2013.05.023

12. Gui Z, Liang W, Liu Y, Zhang Y (2014) Thermo-mechanical behavior of the Al-Si alloy coated hot stamping boron steel. Mater Des 60:26-33. https://doi.org/10.1016/j.matdes.2014.03.011

13. Li N, Lin J, Balint DS, Dean TA (2016) Experimental characterisation of the effects of thermal conditions on austenite formation for hot stamping of boron steel. J Mater Process Technol 231:254-264. https://doi.org/10.1016/j.jmatprotec.2015.12.008

14. Li N, Sun C, Guo N, Mohamed M, Lin J, Matsumoto T, Liu C (2016) Experimental investigation of boron steel at hot stamping conditions. J Mater Process Technol 228:2-10. https://doi.org/10. 1016/j.jmatprotec.2015.09.043

15. Cai J (2011) Modelling of phase transformation in hot stamping of boron steel. Doctoral thesis, Imperial College London, UK

16. Zhou J, Wang B, Huang M (2014) Two constitutive descriptions of boron steel 22MnB5 at high temperature. Mater Des 63:738-748. https://doi.org/10.1016/j.matdes.2014.07.008

17. Kardoulaki E, Lin J, Balint D, Farrugia D (2014) Investigation of the effects of thermal gradients present in Gleeble high-temperature tensile tests on the strain state for free cutting steel. The Journal of Strain Analysis for Engineering Design 49(7):521-532. https://doi. org/10.1177/0309324714531950

18. Ganapathy M, Li N, Lin J, Abspoel M, Bhattacharjee D (2018) A novel grip design for high-accuracy thermo-mechanical tensile testing of boron steel under hot stamping conditions. Exp Mech 58(2):243-258. https://doi.org/10.1007/s11340-017-0333-8

19. Semiatin SL, Ayres RA, Jonas JJ (1985) An analysis of the nonisothermal tensile test. Metall Trans A 16:2299-2308. https:// doi.org/10.1007/BF02670430

20. Peters W, Ranson W (1982) Digital imaging techniques in experimental stress analysis. Opt Eng 21(3):427-431. https://doi.org/10. $1117 / 12.7972925$

21. Chu TC, Ranson WF, Sutton MA (1985) Applications of digitalimage-correlation techniques to experimental mechanics. Exp Mech 25(3):232-244. https://doi.org/10.1007/bf02325092

22. Bruck HA, McNeill SR, Sutton MA, Peters WH (1989) Digital image correlation using Newton-Raphson method of partial differential correction. Exp Mech 29:261-267. https://doi.org/10.1007/ BF02321405

23. Khoo S, Karuppanan S, Tan C (2016) A review of surface deformation and strain measurement using two-dimensional digital image correlation. Metrology and Measurement Systems 23(3):461480. https://doi.org/10.1515/mms-2016-0028

24. Martínez-Donaire AJ, García-Lomas FJ, Vallellano C (2014) New approaches to detect the onset of localised necking in sheets under through-thickness strain gradients. Mater Des 57:135-145. https:// doi.org/10.1016/j.matdes.2014.01.012

25. Güler B, Efe M (2018) Forming and fracture limits of sheet metals deforming without a local neck. J Mater Process Technol 252:477484. https://doi.org/10.1016/j.jmatprotec.2017.10.004

26. Shao Z, Li N, Lin J, Dean TA (2018) Strain measurement and error analysis in thermo-mechanical tensile tests of sheet metals for hot stamping applications. Proc Inst Mech Eng C J Mech Eng Sci 232(11):1994-2008. https://doi.org/10.1177/0954406217714011

27. Shao Z, Li N, Lin J, Dean T (2016) Development of a new biaxial testing system for generating forming limit diagrams for sheet metals under hot stamping conditions. Exp Mech 56(9):14891500. https://doi.org/10.1007/s11340-016-0183-9

28. Zhang R, Shao Z, Lin J (2019) Applications of the digital image correlation (DIC) technique for high-temperature strain measurement: a review. Paper presented at the the 4th international conference on advanced high strength steel and press hardening (ICHSU2018), Hefei, China,

29. Merklein M, Wieland M, Lechner M, Bruschi S, Ghiotti A (2016) Hot stamping of boron steel sheets with tailored properties: a review. J Mater Process Technol 228:11-24. https://doi.org/10.1016/ j.jmatprotec.2015.09.023

30. Li N (2013) Fundamentals of materials modelling for hot stamping of UHSS panels with graded properties. Doctoral thesis, Imperial College London, London, UK

31. Considère A (1885) Mémoire sur l'emploi du fer et de l'acier dans les constructions. Annales des Ponts et Chaussées 9:574-775

32. Ghosh AK (1974) Strain localization in the diffuse neck in sheet metal. Metallurgical Transactions 5(7):1607-1616. https://doi.org/ $10.1007 / \mathrm{bf} 02646332$

33. ASTM International (2016) Standard test methods for tension testing of metallic materials. West Conshohocken, PA. https://doi.org/ 10.1520/E0008 E0008M-16AE01

34. Zhao YH, Guo YZ, Wei Q, Topping TD, Dangelewicz AM, Zhu YT, Langdon TG, Lavernia EJ (2009) Influence of specimen dimensions and strain measurement methods on tensile stress-strain curves. Mater Sci Eng A 525(1-2):68-77. https://doi.org/10.1016/j. msea.2009.06.031

35. Raghavan KS, Wagoner RH (1987) Analysis of nonisothermal tensile tests using measured temperature distributions. Int J Plast 3(1): 33-49. https://doi.org/10.1016/0749-6419(87)90016-7

36. Ushkov SS, Razuvaeva IN, Ivanova LA (1989) Uniform deformation of metals and alloys and its significance in technological plasticity. Strength of Materials 21(4):472-477. https://doi.org/10. 1007/BF01529556 
37. Lin J (2015) Fundamentals of materials modelling for metals processing technologies. Theories and Applications. Imperial College Press, UK. doi:https://doi.org/10.1142/p951

38. Lin J, Mohamed M, Balint D, Dean T (2014) The development of continuum damage mechanics-based theories for predicting forming limit diagrams for hot stamping applications. International Journal of Damage Mechanics 23(5):684-701. https://doi.org/10.1177/1056789513507731

39. Lin J, Liu Y (2003) A set of unified constitutive equations for modelling microstructure evolution in hot deformation. J Mater Process Technol 143:281-285. https://doi.org/10.1016/S09240136(03)00472-2

40. Lin J, Dean TA (2005) Modelling of microstructure evolution in hot forming using unified constitutive equations. J Mater Process
Technol 167(2-3):354-362. https://doi.org/10.1016/j.jmatprotec. 2005.06.026

41. Lin J, Liu Y, Farrugia D, Zhou M (2005) Development of dislocation-based unified material model for simulating microstructure evolution in multipass hot rolling. Philos Mag 85(18):19671987. https://doi.org/10.1080/14786430412331305285

42. Shao Z, Li N, Lin J, Dean T (2017) Formability evaluation for sheet metals under hot stamping conditions by a novel biaxial testing system and a new materials model. Int J Mech Sci 120:149-158. https://doi.org/10.1016/j.ijmecsci.2016.11.022

Publisher's Note Springer Nature remains neutral with regard to jurisdictional claims in published maps and institutional affiliations. 